\section{PREHOSPITAL ANALGESIA IN}

\section{ONTARIO}

To the editor: Paramedics in Ontario provide prehospital care under the direction of their base hospital physicians. Most paramedics are certified at the primary care paramedic (PCP) level, and many communities, especially in rural areas, where transport times are longest, are served exclusively by PCPs. Despite having at least 2 years of college education, PCPs are unable to provide patients with any type of analgesic. We have great respect for the medical directors and would never suggest that we have the definitive answer to this challenging issue. What we would respectfully say is that too many patients are suffering every day in our province because of this deficiency.

Surely, there must be an option for a safe and effective analgesic for PCPs. Australia has had success with methoxyflurane, ${ }^{1,2}$ which has been used prehospitally since the 1970s. ${ }^{3}$ The provincial protocols in Alberta and British Columbia include nitrous oxide (Entonox). Advanced care paramedics in our own province administer morphine or fentanyl. Fentanyl can even be administered in the form of a lollipop and has been successfully used for injured American soldiers in Iraq. ${ }^{4}$ Toradol is another option that is used by some American ambulance services.

This is not about adding skills for the sake of adding skills; this is about the patients and providing them with the best care possible. There are certainly challenges to overcome in adding a new medication to the PCP skill set, and we do not mean to downplay these. Despite their existence, steps must be taken to implement a PCP analgesic. Patients deserve effective pain control from their first contact with the emergency medical system, and this is often in the form of a PCP.

\section{Christopher R. Foerster, MSc,} A-EMCA

Primary Care Paramedic, Lambton EMS, Petrolia, ON

\section{Jeff R. Brooks, A-EMCA, CMM III EMS Executive}

(A) Manager, Emergency Medical Services Department, The County of Lambton, Petrolia, ON

\section{References}

1. Buntine $\mathrm{P}$, Thom O, Babl F, et al. Prehospital analgesia in adults using inhaled methoxyflurane. Emerg Med Australas 2007;19:509-14, doi:10.1111/ j.1742-6723.2007.01017.x.

2. Babl FE, Jamison SR, Spicer M, et al. Inhaled methoxyflurane as a prehospital analgesic in children. Emerg Med Australas 2006;18:404-10, doi:10.1111/ j.1742-6723.2006.00874.x.

3. National Prescribing Service Rational Assessment of Drugs and Research. Methoxyflurane (Penthrox) for analgesia (doctor's bag listing). Available at: http:// www.nps.org.au/health_professionals/ publications/nps_radar/2010/may_ 2010/methoxyflurane (accessed May 1 2011).

4. Kotwal RS, O'Connor KC, Johnson TR, et al. A novel pain management strategy for combat casualty care. Ann Emerg Med 2004;44:121-7, doi:10.1016/j.annemergmed.2004.03.025. 